\title{
Insecticide treatments disinfest nursery citrus of glassy-winged sharpshooter
}

\author{
Elizabeth E. Grafton-Cardwell \\ Christopher A. Reagan \\ Yuling Ouyang
}

To protect uninfested areas of California from glassy-winged sharpshooter (GWSS), the disinfestation of citrus nursery stock prior to shipment is essential. A nonnative insect, GWSS transmits the bacterium that causes Pierce's disease in grapevines. In our study, GWSS adults were especially sensitive to two categories of insecticides, the pyrethroids and systemically applied neonicotinoids. Several insecticides, including the carbamate carbaryl and a few of the foliar neonicotinoids were highly effective in preventing GWSS nymphs from successfully emerging from egg masses. While no pesticide treatment will perfectly protect nursery citrus, a treatment plan that includes a combination of insecticides that are effective against adults and emerging nymphs will minimize the chance of transporting GWSS throughout California.

lassy-winged sharpshooter

(GWSS), a nonnative insect, arrived in Southern California prior to 1990 (Sorenson and Gill 1996). However, it was not until the late 1990s that the serious nature of its potential as a vector of Xyllela fastidiosa, the bacterium that causes Pierce's disease in grapes, was recognized in California. From 1997 to 2000, the number of grapevines infected with Pierce's disease in Temecula, Calif., rapidly escalated from a small number to thousands (Blua et al. 1999). This epidemic pointed out to the grape industry the seriousness of GWSS as a vector of Pierce's disease.

Glassy-winged sharpshooter (Homal-

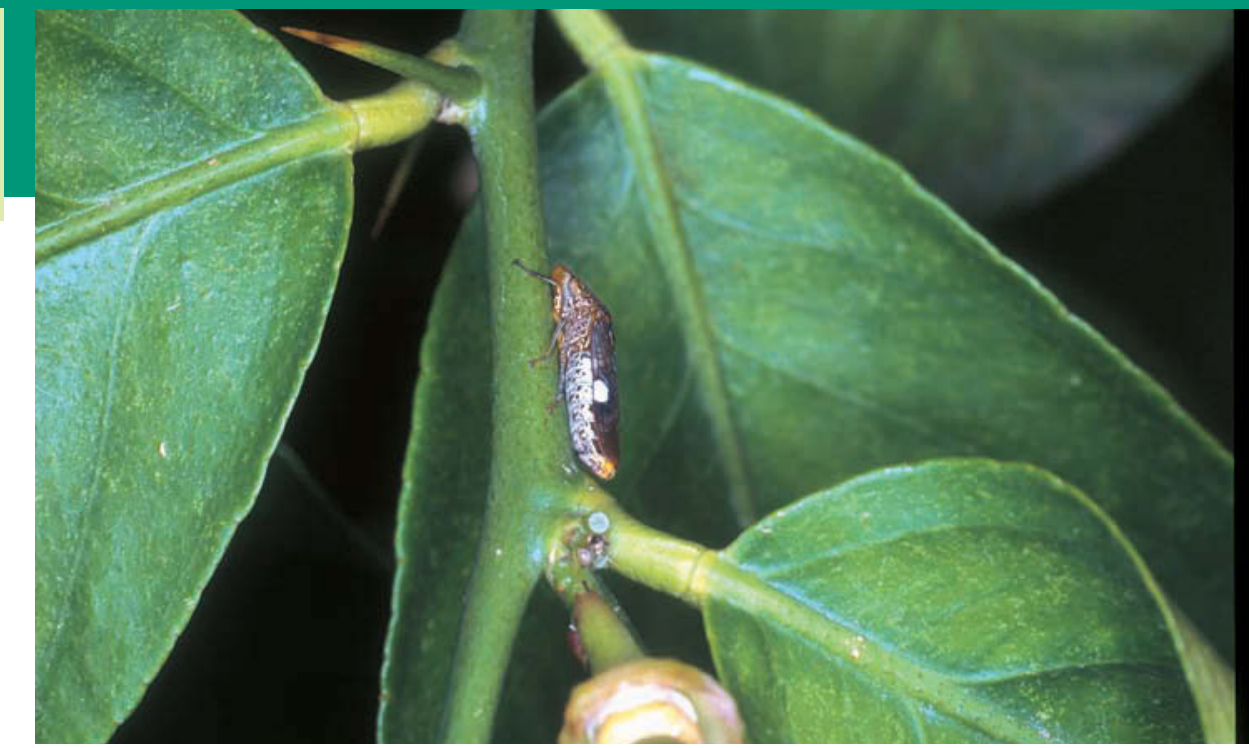

The glassy-winged sharpshooter (GWSS) was recognized as a serious insect pest in California in the mid-1990s. Subject to quarantine restrictions, nursery citrus is usually treated with insecticides to prevent the transport of GWSS throughout the state.

Above, A GWSS adult rests on a citrus stem.

odisca coagulata) entered the southern San Joaquin Valley in the mid-1990s and has been gradually spreading northward along the citrus belt. It now infests citrus in most of Kern County and portions of southern Tulare County. Citrus is a preferred oviposition (egg-laying) host of GWSS; grapes located near citrus are at greater risk for Pierce's disease (Perring et al. 2001).

The bacterium that causes Pierce's disease blocks the water-conducting cells of the grapevine, causing leaves to become scorched, fruit to shrivel and canes to grow poorly. Currently there are no resistant rootstocks or treatments for Pierce's disease once a vine

is infected, so the only control measures available to growers are roguing out infected vines and reducing the sharpshooter vectors with insecticide treatments. Since GWSS has numerous hosts, eradication with insecticides

is impossible. Preventing GWSS from being artificially transported into uninfested regions is critical, to buy time for research and regulatory programs to develop additional control strategies.

A series of quarantine laws went into effect between 2000 and 2002 to prevent the movement of GWSS nymphs, adults and eggs on landscape ornamentals, bulk grapes, bulk citrus and nursery citrus to uninfested areas of California. Citrus nurserymen accomplish disinfestation of their trees by insecticide treatments, and careful visual inspection and hand removal of GWSS egg masses prior to shipment. These measures have greatly reduced the number of nursery shipments rejected at destination due to GWSS infestation. However, citrus nurserymen need better information about which insecticides are most effective and how long they last. Many have treated their nurseries at frequent intervals and rotated through various insecticides without full knowledge of their efficacy. Since nursery operators often do not know exactly when plants will be shipped, they must be confident that insecticides will be toxic to GWSS for at least several weeks. Our experiments were conducted to determine the residual effect of various pesticides on adult GWSS survival, their ability to deposit eggs and the ability of nymphs to emerge from egg masses. 


\section{Adult GWSS tests}

In 2001, we tested commercial applications of several insecticides at an Arvin nusery, using 66 'Eureka' lemon on volkameriana rootstock and $66^{\prime} \mathrm{Ne}$ whall' navel oranges on Schaub rough lemon rootstock (15-gallon potted plants)(table 1). Foliar insecticides were mixed using field rates in 750 gallons of water and trees were sprayed to runoff using a Hudson-type pump sprayer. Systemic insecticides were diluted in 500 milliliters $(\mathrm{ml})$ water per pot and applied to moistened soil. About 1 liter of water was added to each pot immediately after treatment. The soil of all trees was hand-watered every 2 to 3 days. Half of the trees were additionally irrigated using overhead sprinklers for 30 minutes, three times per week. Trees were kept in a commercial greenhouse where the temperature fluctuated between $60^{\circ} \mathrm{F}$ and $85^{\circ} \mathrm{F}$.

GWSS adults were collected at weekly intervals in an untreated Bakersfield citrus orchard from August to October 2001, using sweep nets. Each week, freshly collected adults were caged on six trees per treatment (five adults per cage, six cages per treatment, one cage per tree) using polyester paint-strainer bags. The number of live adults after 24 hours and number of egg masses deposited after 7 days were recorded each week for 11 weeks after treatments. During the first week, the mortality of adults was not measured after the first 24 hours. When GWSS adults survived 24 hours of an insecticide treatment and
TABLE 1. Insecticides and rates tested for efficacy against GWSS

\begin{tabular}{|c|c|c|c|c|}
\hline Insecticide & Trade name & Class & $\begin{array}{c}\text { Formulated rate } \\
\text { applied }\end{array}$ & $\begin{array}{l}\text { lb Al/acre or } \\
\text { cubic ft soil* }\end{array}$ \\
\hline Acetamiprid & Assail 70 WP & Neonicotinoid foliar & $0.36 \mathrm{lb}$ & 0.25 \\
\hline Bifenthrin & Talstar F & Pyrethroid foliar & $187.5 \mathrm{oz}$ & 0.98 \\
\hline Buprofezin & Applaud 70 WP & \multicolumn{2}{|c|}{ Insect growth regulator foliar $2.86 \mathrm{lb}$} & 2.0 \\
\hline Carbaryl & Sevin XLR Plus & Carbamate foliar & $8 \mathrm{pt}$ & 4.0 \\
\hline Chlorpyrifos & Lorsban $4 \mathrm{E}$ & Organophosphate foliar & $12 \mathrm{pt}$ & 6.0 \\
\hline Dinotefuran & V-10112 20 SG & Neonicotinoid foliar & $0.66 \mathrm{lb}$ & 0.13 \\
\hline Dinotefuran & V-10112 20 SG & Neonicotinoid foliar & $1.65 \mathrm{lb}$ & 0.33 \\
\hline Fenpropathrin & Tame 2.4 EC & Pyrethroid foliar & $60 \mathrm{oz}$ & 1.125 \\
\hline Imidacloprid & Marathon II & Neonicotinoid foliar & $12.68 \mathrm{oz}$ & 0.20 \\
\hline Imidacloprid & Provado $1.6 \mathrm{~F}$ & Neonicotinoid foliar & $15.83 \mathrm{oz}$ & 0.20 \\
\hline Imidacloprid & Admire $2 \mathrm{~F}$ & Neonicotinoid systemic & $0.025 \mathrm{oz} / \mathrm{ft}^{3}$ soilt & $0.0004 / \mathrm{ft}^{3}$ \\
\hline Thiomethoxam & Platinum 2 SC & Neonicotinoid systemic & 11 oz/acre & 0.17 \\
\hline Thiomethoxam & Actara 25 WG & Neonicotinoid foliar & $0.09 \mathrm{lb}$ & 0.023 \\
\hline
\end{tabular}

deposited eggs over the 7-day exposure period, that treatment was no longer tested. At the end of each 7-day interval, living adults were removed and destroyed, and freshly captured adults were caged on new branches.

Adult mortality. Residues began to break down - as evidenced by more than one adult surviving a 24-hour period -2 weeks after treatments were applied for the organophosphate chlorpyrifos (Lorsban), 3 weeks for the carbamate carbaryl (Sevin), and 2 and 4 weeks for the foliar neonicotinoids imidacloprid (Marathon) and acetamiprid (Assail)(table 2). We

do not have adult mortality data for the first week after treatment, so the chlorpyrifos treatment may have had an even shorter residual effect. The systemic neonicotinoid imidacloprid (Admire) allowed only an occasional adult to survive for 8 weeks following treatment, and the systemic neonicotinoid
TABLE 2. Number of live GWSS adults $\mathbf{2 4}$ hours after exposure to insecticide residuesnumber of egg masses deposited during 7-day exposure period*

\begin{tabular}{|c|c|c|c|c|c|c|c|c|c|c|c|}
\hline \multirow[b]{2}{*}{ Treatment } & \multicolumn{11}{|c|}{ Weeks after treatment } \\
\hline & 1 & 2 & 3 & 4 & 5 & 6 & 7 & $8 t$ & 9 & 10 & 11 \\
\hline Untreated & -2 & $26-0$ & $22-5$ & $28-3$ & $25-12$ & $21-4$ & $22-7$ & $28-0$ & $27-$ & $17-$ & $22-$ \\
\hline Chlorpyrifos & -2 & $26-11$ & & & & & & & & & \\
\hline Carbaryl & -0 & $0-2$ & $14-1$ & & & & & & & & \\
\hline \multicolumn{12}{|l|}{ Neonicotinoids: } \\
\hline Acetamiprid & -0 & $0-0$ & $1-0$ & $6-1$ & & & & & & & \\
\hline Imidacloprid (foliar) & -2 & $11-0$ & $6-0$ & $6-0$ & $5-3$ & & & & & & \\
\hline Imidacloprid (systemic) & -0 & $1-0$ & $0-0$ & $0-0$ & $0-0$ & $1-0$ & $0-0$ & $1-0$ & $17-$ & & \\
\hline Thiomethoxam (systemic) & -0 & $0-0$ & $0-0$ & $0-0$ & $0-0$ & $0-0$ & $0-0$ & $0-0$ & $0-$ & $0-$ & $0-$ \\
\hline \multicolumn{12}{|l|}{ Pyrethroids: } \\
\hline Fenpropathrin & -0 & $0-0$ & $0-0$ & $0-1$ & $0-0$ & $0-0$ & $0-0$ & $0-0$ & $0-$ & $0-$ & $0-$ \\
\hline Bifenthrin & -0 & $1-0$ & $0-0$ & $0-0$ & $0-0$ & $0-0$ & $0-0$ & $0-0$ & $0-$ & $0-$ & $0-$ \\
\hline $\begin{array}{l}\text { Fenpropathrin }+ \\
\text { imidacloprid (foliar) }\end{array}$ & -0 & $0-0$ & $0-0$ & $0-0$ & $0-0$ & $1-0$ & $2-0$ & 3-0 & $3-$ & & \\
\hline
\end{tabular}

* Treatments applied Aug. 17, 2001; 30 individuals tested per treatment.

† Oviposition stopped Oct. 11, 2001 thiomethoxam (Platinum, unregistered) caused complete mortality of adults for 11 weeks. The pyrethroids fenpro-pathrin (Tame) and bifenthrin (Talstar) were highly effective; bifenthrin allowed only one adult to survive 24 hours and fenpropathrin allowed no adults to survive over the 11-week test period. Combining foliar imidacloprid and fenpropathrin seemed to reduce efficacy compared to fenpropathrin alone. We saw no effect of the host plant (lemons or oranges) on the mortality of adult GWSS.

Egg masses deposited. In this same experiment, we evaluated the number of eggs that GWSS were able to deposit during the 7 days after placement of adults on the insecticide residues (table 2). Egg masses were found 1 week after application in the chlorpyrifos and foliar imidacloprid treatments, and during week 2 in the carbaryl treatment. These insecticides had a short residual effect on egg deposition. The foliar neonicotinoid acetamiprid prevented egg-laying for 3 weeks. The fenpropathrin treatment allowed one egg mass to be deposited during week 4 . The other treatments (systemic imidacloprid, systemic thiomethoxam and bifenthrin) did not allow a single egg to be deposited during the 8-week experiment. On Oct. 11, 2001, the field-collected GWSS adults halted oviposition, so this portion of the experiment could not be continued. We saw no effect of the host plant (lemons or oranges) on egg production of GWSS.

Overhead irrigation. We compared GWSS adult survival during 24 hours on treated trees with overhead irrigation (applied for 30 minutes, three times per week), and without overhead watering (table 3). There was a significant reduc- 


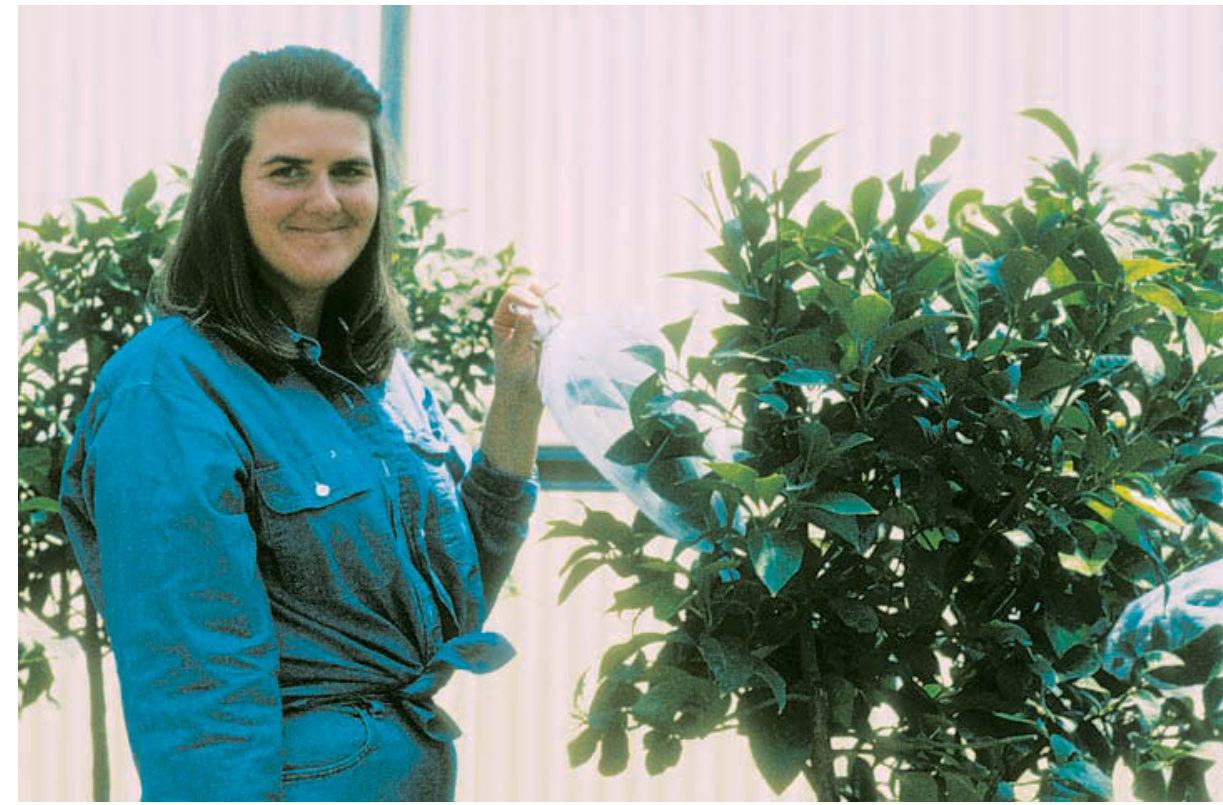

Various insecticides were tested on citrus for their effectiveness in controlling GWSS nymphs and adults. Laboratory assistant Becky Striggow placed GWSS adults in cloth cages on treated citrus trees to test their response.

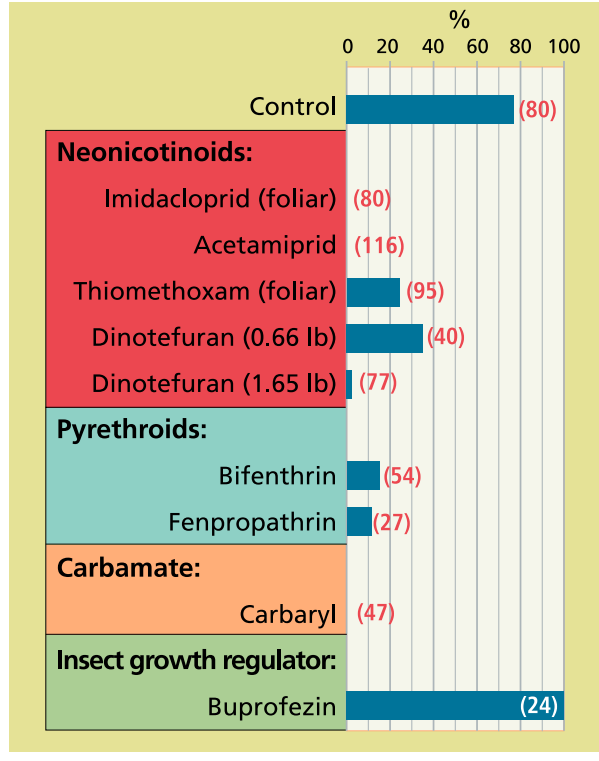

Fig. 1. Percentage of nymphs that successfully emerged from egg masses treated with various insecticides (and total number of eggs tested). tion in toxicity of the insecticides due to overhead watering during week 4 for carbaryl, weeks 2 through 4 for acetamiprid, weeks 4 and 5 for

foliar imidacloprid, weeks 6, 8 and 9 for fenpropathrin, and during weeks 5 to 9 for fenpropathrin and the fenpro-pathrin plus foliar imidacloprid combination. We found that overhead watering reduces the toxicity of foliar insecticides and should be avoided. The exception was bifenthrin, which was highly effective under all application conditions. The systemic neonicotinoids (imidacloprid and thiomethoxam) did not appear to be significantly affected by overhead watering during the first

9 weeks of the experiment.

\section{Emergence from egg masses}

In the second experiment, GWSS adults were collected weekly from an unsprayed citrus orchard in Kern County during September 2002 and caged for 1 week on nursery citrus

(15-gallon potted lemons and oranges of the same varieties as the 2001 test). After egg masses were deposited, the adults were removed and the trees were treated using a 1-liter hand-pump sprayer with commercial rates of various insecticides to determine if nymphs could successfully emerge from the egg masses. This process was repeated three times to obtain results for eight different insecticides. At the time of treatment, eggs

TABLE 3. Number of surviving GWSS adults 24 hours after placement on insecticide residues without overhead watering-with overhead watering*

\begin{tabular}{|c|c|c|c|c|c|c|c|c|c|c|}
\hline \multirow[b]{2}{*}{ Treatment } & \multicolumn{10}{|c|}{ Weeks after treatment } \\
\hline & 2 & 3 & 4 & 5 & 6 & 7 & 8 & 9 & 10 & 11 \\
\hline Untreated & $26-29$ & $22-20$ & $28-25$ & $25-23$ & $21-27$ & $22-25$ & $28-26$ & $27-27$ & $17-27$ & $22-27$ \\
\hline Chlorpyrifos & $26-28$ & & & & & & & & & \\
\hline Carbaryl & $0-10$ & $14-13$ & $4-27$ & & & & & & & \\
\hline \multicolumn{11}{|l|}{ Neonicotinoids: } \\
\hline Acetamiprid & $0-12$ & $1-4$ & $6-16$ & & & & & & & \\
\hline Imidacloprid (foliar) & $11-10$ & $6-2$ & $6-15$ & $5-8$ & & & & & & \\
\hline Imidacloprid (systemic) & $1-3$ & $0-0$ & $0-2$ & $0-0$ & $1-2$ & $0-0$ & $1-3$ & $17-10$ & & \\
\hline Thiomethoxam (systemic) & $\Rightarrow 0-0$ & $0-0$ & $0-0$ & $0-0$ & $0-0$ & $0-0$ & $0-0$ & $0-0$ & $0-5$ & \\
\hline \multicolumn{11}{|l|}{ Pyrethroids: } \\
\hline Fenpropathrin & $0-0$ & $0-0$ & $0-0$ & $0-1$ & $0-3$ & $0-0$ & $0-12$ & $0-12$ & & \\
\hline Bifenthrin & $1-0$ & $0-0$ & $0-0$ & $0-0$ & $0-0$ & $0-0$ & $0-0$ & $0-0$ & $0-0$ & $0-0$ \\
\hline $\begin{array}{l}\text { Fenpropathrin } \\
+ \text { imidacloprid (foliar) }\end{array}$ & $0-0$ & $0-0$ & $0-1$ & $0-7$ & $1-5$ & $2-18$ & $3-17$ & $3-18$ & & \\
\hline
\end{tabular}

* Treatments applied Aug. 17, 2001; 30 individuals tested per treatment.

ranged in age from 1 to 6 days. Successful emergence was defined as nymphs that completely emerged from the egg cell and fully developed their nymphal form (legs and dark body color).

Foliar imidacloprid (Provado), acetamiprid and carbaryl did not allow any nymphs to successfully emerge from the egg masses (fig. 1). The nymphs either died inside the egg cell or as they began to emerge from the egg cell. The foliar neonicotinoids thiomethoxam (Actara) and dino-tefuran, and the pyrethroids fenpropathrin and bifenthrin, allowed $5 \%$ to $40 \%$ of nymphs to successfully emerge. Some foliar neonicotinoids are more effective than others, and in the case of dinotefuran, the insecticide application rate is important. Buprofezin (Applaud), an insect growth regulator, did not have any effect on nymphal emergence, an unsurprising result since this insecticide affects GWSS when it is molting. The significance of preventing nymphs from successfully emerging is to prevent them from moving to untreated surfaces and surviving transportation to uninfested regions of California. Insecticides that show complete mortality of emerging nymphs are the most suitable for citrus nursery treatments.

GWSS adults and nymphs emerging from egg masses differed in their responses to the insecticides tested. The pyrethroids and systemically applied 


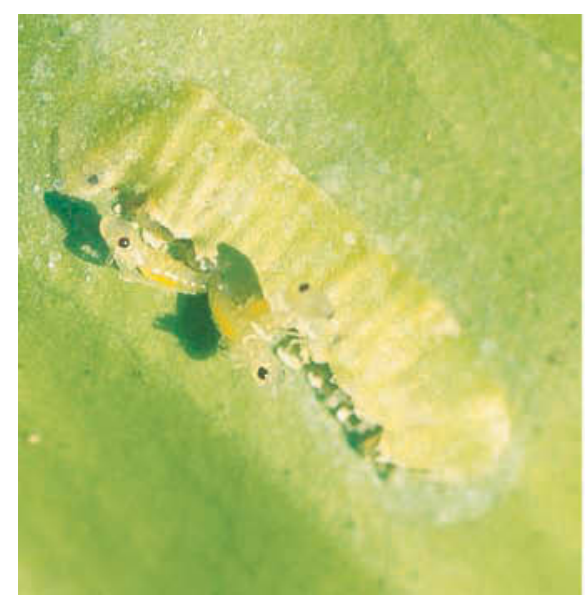

GWSS nymphs as they emerge from the egg case.

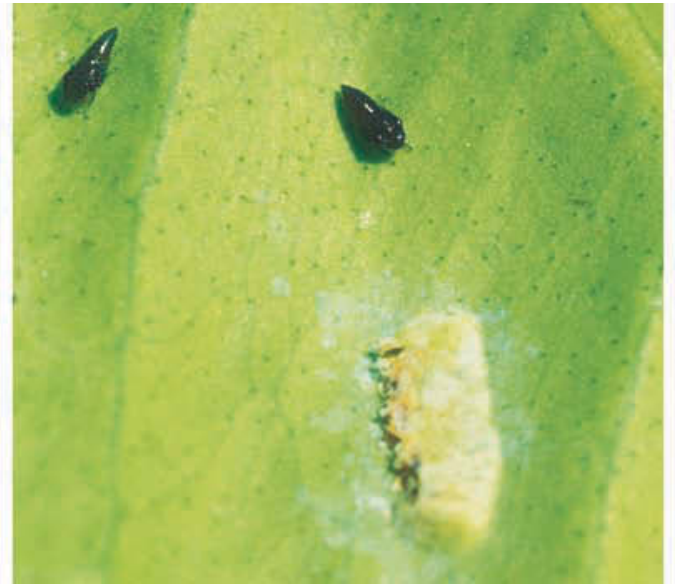

The nymphs turn a dark color and develop legs soon after emergence.

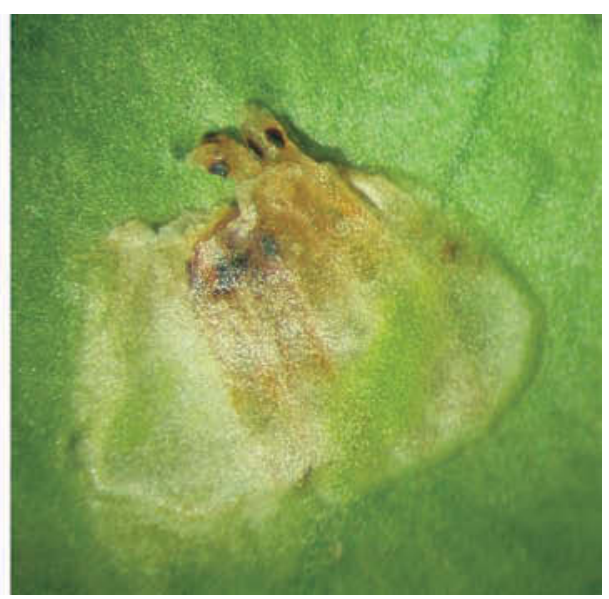

Imidacloprid kills GWSS nymphs as they try to emerge from the egg case. neonicotinoids were the most effective against the adult stage, limiting their survival and ability to deposit eggs. These insecticides should be used as the first line of defense. Any insecticide that eliminates adults is likely to also eliminate emerged nymphs, because of their smaller size. Sometimes, GWSS adults are able to deposit eggs before the insecticides kill them (table 2). The carbamate carbaryl and the foliar neonicotinoids imidacloprid (Provado) and acetamiprid were highly effective in preventing nymphs from successfully emerging from egg masses.

\section{Advice for citrus nurseries}

Based on these experiments, we advise citrus nursery operators to apply a systemic neonicotinoid 1 to 8 weeks before shipment is expected. Systemic imidacloprid (Bayer CropScience) is the only one currently registered for nursery citrus. Treatment with systemic imida-cloprid at least 1 week prior to shipment is needed to ensure uptake into the tree. The foliage should be visually inspected at the time of shipment and any sharpshooter egg masses found should be removed and destroyed.

Just prior to shipment, a pyrethroid such as fenpropathrin or bifenthrin should be applied to ensure that the foliage is disinfested of nymphs and adults. This is especially important if the trees were not treated with systemic imidacloprid within the 1- to 8-week time frame. This treatment is effective for up to 8 weeks, so no additional adulticide is needed if shipments are delayed within that time period. In ad- dition, carbaryl, acetamiprid or foliar imidacloprid (Provado) should be applied just prior to shipment (1 to 3 days) to prevent nymphs from emerging from egg masses that were not found during the visual search.

Our results confirm previous research on controlling GWSS. Bethke and Redak (2001, 2002a, 2002b) and Bethke et al. (2001) demonstrated similar efficacy of systemic neonicotinoids and pyrethroids against adult GWSS and efficacy of carbaryl against emerging nymphs for nursery ornamentals. Akey et al. (2001) and Grafton-Cardwell et al. (2001) demonstrated the efficacy of pyrethroids and neonicotinoids for GWSS in commercial grapes and citrus. These recommendations should reduce insecticide use in nurseries because operators will be able to apply the most effective insecticides at the right time. In addition, they will have confidence that the pyrethroid and systemic neonicotinoid residues will remain effective for a number of weeks if shipment is delayed.

\section{E.E. Grafton-Cardwell is IPM Specialist} and Research Entomologist, Department of Entomology, UC Riverside, stationed at Kearney Agricultural Center (KAC); C.A. Reagan is Staff Research Associate, Lindcove Research and Extension Center; and Y. Ouyang is Staff Research Associate, KAC. This project was supported by funds from the California Citrus Nursery Advisory Board. The authors thank Gary Moles and Mark Campbell of Willits and Newcomb Nursery (Arvin, Calif.) for gener- ously providing citrus trees and facilities, and Ping Gu, Greg Montez, Rebecka Striggow and Alison Wohlgemuth for technical assistance. We thank Aventis, Bayer CropScience, Dow AgroSciences, FMC Corporation, Nichino America, Syngenta Crop Protection and Valent Agricultural Products for financial support and insecticides.

\section{References}

Akey DH, Henneberry TJ, Toscano NC. 2001. Insecticides sought to control adult glassy-winged sharpshooter. Cal Ag 55(4):22-7.

Bethke JA, Blua MJ, Redak RA. 2001. Effect of selected insecticides on Homalo-disca coagulata (Homoptera: Cicadellidae) and transmission of oleander leaf scorch in a greenhouse study. J Econ Entomol 94:1031-6.

Bethke JA, Redak RA. 2001. Control of adult sharpshooters on Poinsettia under greenhouse conditions, summer 2000. Arthropod Management Tests 26:G51.

Bethke JA, Redak RA. 2002a. Control of adult glassy-winged sharpshooters on liquidambar under greenhouse conditions, summer 2001. Arthropod Management Tests 27:G51.

Bethke JA, Redak RA. 2002b. Control of glassy-winged sharpshooter egg masses on chrysanthemum under greenhouse conditions using selected pesticides, summer 2001. Arthropod Management Tests 27:G29.

Blua MJ, Phillips PA, Redak RA. 1999. A new sharpshooter threatens both crops and ornamentals. Cal Ag 53(2):22-5.

Grafton-Cardwell B, Reagan C, Kallsen C, Bartels M. 2001. Glassy-winged sharpshooter in San Joaquin Valley citrus. UC Plant Protection Quarterly 11(2):4-7.

Perring TM, Farrar CA, Blua MJ. 2001. Proximity to citrus influences Pierce's disease in Temecula Valley vineyards. Cal $\mathrm{Ag}$ 55(4):13-8.

Sorensen SJ, Gill RJ. 1996. A range extension of Homalodisca coagulata (Say) (Hemiptera: Clypeorrhyncha: Ciacadel-lidae) to southern California. Pan-Pac Entomol 72:160-1. 